\title{
PII: S0038-1098(98)00386-X
}

\section{CORRELATION OF COMPENSATION IN Si-DOPED GaAs BETWEEN ELECTRICAL AND OPTICAL METHODS}

\author{
Mantu Kumar Hudait ${ }^{a, b}$ and S.B. Krupanidhi ${ }^{a, *}$ \\ ${ }^{a}$ Materials Research Centre, Indian Institute of Science, Bangalore-560 012, India \\ ${ }^{b}$ Central Research Laboratory, Bharat Electronics, Bangalore-560 013, India
}

(Received 9 June 1998; accepted 3 August 1998 by H. Akai)

\begin{abstract}
The compensation in Si-doped GaAs by metal organic vapor phase epitaxy was studied as a function of electron concentration and growth temperature by means of photoluminescence and Hall effect measurements. The PL spectra show peaks due to $\mathrm{Si}$ donor-Si acceptors $\left(\mathrm{Si}_{\mathrm{Ga}}-\mathrm{Si}_{\mathrm{As}}\right)$ and $\mathrm{Si}$-related complex-defects transitions, which may be attributed to Si donor coupled to a group III elemental vacancy $\left(\mathrm{Si}_{\mathrm{Ga}}-\mathrm{V}_{\mathrm{Ga}}\right)$ complexes. We showed the importance of each of these defects pair to the optical properties, as it is strongly dependent on the growth parameters. The defects pair are responsible for autocompensation and confirmed by electrical measurements. (C) 1998 Elsevier Science Ltd. All rights reserved
\end{abstract}

Keywords: A. semiconductors, B. photoluminescence, C. optical properties.

\section{INTRODUCTION}

It is now well established that the $\mathrm{Si}$-doped $\mathrm{GaAs}$ epitaxial layers are routinely employed at moderate to heavy doping levels in many devices of interest. For example, in $p^{+}-n$ GaAs solar cells they form the base and buffer layers of $n^{+}$-GaAs of $1 \times 10^{18} \mathrm{~cm}^{-3}$ can be used to provide back-surface reflection of minoritycarriers and an increase in the photovoltaic conversion efficiency. In high performance submicrometer GaAsMESFETs, highly doped $\left(\sim 1 \times 10^{18} \mathrm{~cm}^{-3}\right)$ channel layers have been employed [1]. Being a group IV element, it exhibits self-compensation to a much smaller extent. It is well accepted that at low Si concentrations, the $\mathrm{Si}$ atoms enter into the lattice mainly as a simple substitutional impurity at the group III element sites $(\mathrm{Ga})$, acting as a donor $\left(\mathrm{Si}_{\mathrm{Ga}}\right)$ and at the As sites, acting as an acceptor $\left(\mathrm{Si}_{\mathrm{As}}\right)$ [2-5]. The latter becoming increasingly important as the $\mathrm{Si}$ concentration increases, causing a saturation of the free electron concentration. Heavily doped films present a strong compensation of the free electron concentration. This compensation has been attributed in GaAs mainly to a complex defect formed by

\footnotetext{
* Corresponding author. E-mail: sbk@mrc.iisc.ernet.in
}

a donor atom coupled to a group III element vacancy $\left(\mathrm{Si}_{\mathrm{Ga}}-\mathrm{V}_{\mathrm{Ga}}\right)$, the so-called self-activating center [6]. This complex defect give rise to a broad photoluminescence line centered about $1.2 \mathrm{eV}$ for GaAs [7] and $1.35 \mathrm{eV}$ for $\mathrm{Al}_{0.3} \mathrm{Ga}_{0.7} \mathrm{As}$ [6] samples. Another deep photoluminescence feature about $1.05-1.28 \mathrm{eV}$ has been attributed to a $\mathrm{Si}_{\mathrm{Ga}}-\mathrm{Si}_{\mathrm{As}}$ pair defect $[8,9]$ and responsible for the compensation. Maguire et al. [10] investigated Si doped GaAs by using local vibration modes (LVM), Hall effect and secondary ion mass spectroscopy (SIMS) and concluded that the $[\mathrm{Si}-\mathrm{X}]$ was tentatively attributed to the well-known self-activated center $\left(\mathrm{Si}_{\mathrm{Ga}}-\mathrm{V}_{\mathrm{Ga}}\right)$. The LVM results do not necessarily exhaust the possibilities of forms of $\mathrm{Si}$ incorporation. Souza and Rao [8] mentioned that in GaAs, the $\mathrm{Si}$ incorporation is extremely complex and highly dependent on growth conditions. Photoluminescence and electrical experimental studies, such as Hall effect measurements were used to understand the dopant behavior at high doping concentrations and growth temperatures. In this communication, we show some evidence of the presence of $\mathrm{Si}_{\mathrm{Ga}}-\mathrm{Si}_{\mathrm{As}}$ pair defects by studying Si doped GaAs grown under different silane $\left(\mathrm{SiH}_{4}\right)$ partial pressures and different growth temperatures. These $\mathrm{Si}_{\mathrm{Ga}}-\mathrm{Si}_{\mathrm{As}}$ defect pairs are responsible for reducing free-carrier concentration of higher $\mathrm{Si}$ doping levels due to compensation effects. 


\section{EXPERIMENTAL DETAILS}

The Si-doped GaAs epitaxial layers were grown by metal organic vapor phase epitaxy (MOVPE) on semiinsulating GaAs $\left(\begin{array}{lll}1 & 0 & 0\end{array}\right)$ substrates with an offset by $2^{\circ}$ towards $\left[\begin{array}{lll}1 & 1 & 0\end{array}\right]$ direction. The source materials were trimethylgallium (TMGa), arsine $\left(\mathrm{AsH}_{3}\right),(104 \mathrm{ppm})$ silane $\left(\mathrm{SiH}_{4}\right)$ as an $n$-type dopant and palladium purified $\mathrm{H}_{2}$ as a carrier gas. During the growth, the pressure inside was kept at 100 Torr and the growth temperature was varied from $600^{\circ} \mathrm{C}$ to $725^{\circ} \mathrm{C}$. TMGa and $\mathrm{AsH}_{3}$ flow rate was varied from 10 to 20 SCCM and 30 to 50 SCCM, respectively. The total flow rate was about 2 SLPM. The doping concentrations were determined by using Hall measurement. Hall effect measurements (Van der Pauw method) were carried out at $300 \mathrm{~K}$ to determine the mobility (Hall factor $r_{\mathrm{H}}=1$ ). $N$-type layers with thicknesses of about $2 \mu \mathrm{m}$ were chosen for analysis to reduce thickness measurement errors. Electron densities in the range of $1 \times 10^{17}-1.5 \times 10^{18} \mathrm{~cm}^{-3}$ were measured. Low temperature $(4.2 \mathrm{~K})$ photoluminescence (LTPL) measurements using $5145 \AA$ excitation from an argon ion laser and $100 \mathrm{~mW}$ laser power were carried out.

\section{RESULTS AND DISCUSSION}

Figure 1 shows the electron concentration as a function of $\mathrm{SiH}_{4}$ partial pressure. The electron concentration increases monotonically with $\mathrm{SiH}_{4}$ mole fraction, which is consistent to that reported by Bass [11] and compensates at the concentration of $1.5 \times 10^{18} \mathrm{~cm}^{-3}$. In MOVPE growth, $\mathrm{Si}$, the amphoteric dopant is found to incorporate preferentially on one sublattice over a fairly

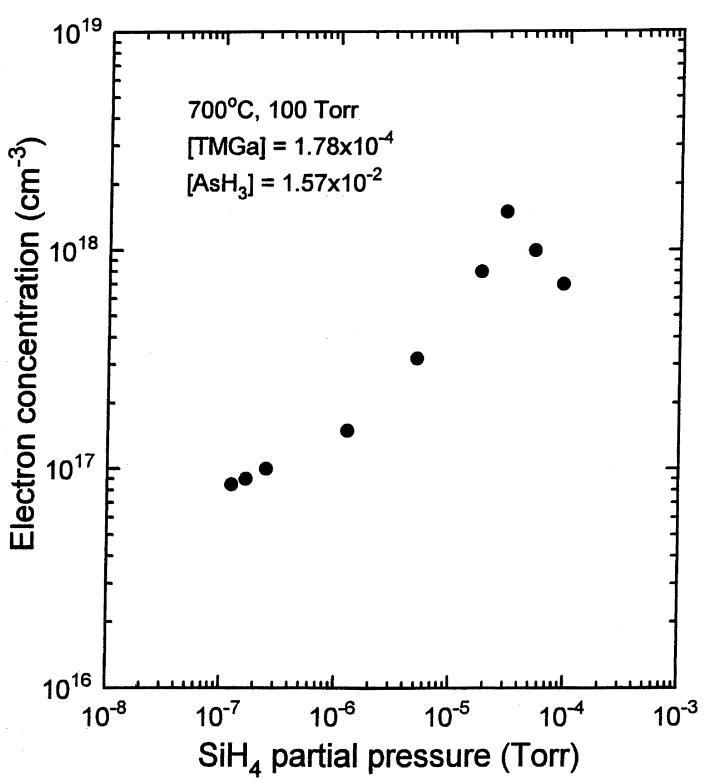

Fig. 1. Electron concentration of Si-doped GaAs as a function of $\mathrm{SiH}_{4}$ partial pressure. wide range of dopant concentrations. At higher dopant concentrations, population of the other sublattices can become energetically more favourable resulting in both donor and acceptor formation. This autocompensation limits the maximum carrier concentration that can be achieved in the semiconductor with an amphoteric dopant. The incorporation of an amphoteric dopant on a particular site is considered to result from the combination of thermodynamic, electronic and chemical effects [12]. The electron concentration increases with increasing $\mathrm{SiH}_{4}$ partial pressure up to $2.9 \times 10^{-5}$ Torr and then decreases, due to autocompensation. As the $\mathrm{SiH}_{4}$ partial pressure increases further, the inactivated concentration increased relatively with the doped concentration, indicating the limits of free carrier concentration. The decrease of free-carrier concentration in heavily doped $n$-type GaAs is a well-known phenomenon based upon two main models. One involves amphoteric native defects with strong Fermi level dependent defect formation energy $[13,14]$ and the other involves electronic occupation of a highly localized state of the donor-related DX center [15]. There are at least other two possible mechanisms responsible for the reduction in the number of electrons: (1) inactivation of the Si donors, i.e. complex formation and (2) charge compensation, i.e. generation of remote acceptors. Subsequently, the actual quantification of Si-atomic concentration would confirm the possible mechanisms and these studies are in progress in terms of secondary ion mass spectroscopy (SIMS). In the recent study of Si doped GaAs by Fushimi et al. [16], they pointed out that the limit of free-carrier concentration in the heavily doped layers is caused by gallium vacancy $\left(\mathrm{V}_{\mathrm{Ga}}\right.$ ) and not by electron occupation of a highly localized state of the donor-related DX center. This autocompensation can be confirmed by taking the optical properties of the films using LTPL spectroscopy.

Figure 2 shows the photoluminescence spectra at $4.2 \mathrm{~K}$ in the concentration range of $1 \times 10^{17}$ $1.5 \times 10^{18} \mathrm{~cm}^{-3}$ for the samples studied in Fig. 1. The spectra were measured with $\mathrm{LN}_{2}$ cooled Ge photodetector whose operating range is about $0.7-1.9 \mathrm{eV}$, while resolution was kept at about $0.5 \mathrm{meV}$. The excitonic PL main peak energy shifted to higher energy as the electron concentration increased, which is primarily due to Burstein-Moss effect [17]. According to Burstein and Moss [17], this shift results from the filling of the conduction band. From Fig. 2, it is seen that the sample is autocompensated, when the electron concentration greater than $1.5 \times 10^{18} \mathrm{~cm}^{-3}$ in our present growth conditions. The PL spectra corresponding to the electron concentrations $1 \times 10^{18} \mathrm{~cm}^{-3}$ and $7 \times 10^{17} \mathrm{~cm}^{-3}$ are plotted as inset in Fig. 2. In addition to the near band peak, one observes a broad band with different peaks at around 1.05 and $1.2558 \mathrm{eV}$. The presence of these peaks 


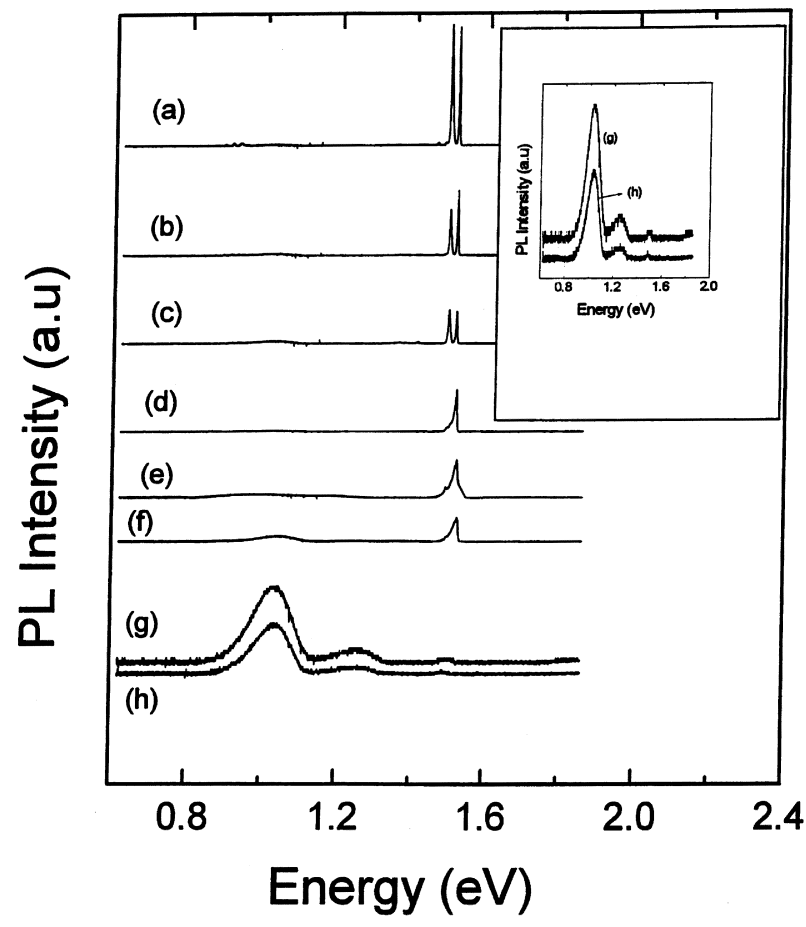

Fig. 2. 4.2 K PL spectra of Si-doped GaAs epilayers for various electron concentrations. The electron concentrations are (a) $1 \times 10^{17} \mathrm{~cm}^{-3}$, (b) $1.5 \times$ $10^{17} \mathrm{~cm}^{-3}$, (c) $3.2 \times 10^{17} \mathrm{~cm}^{-3}$, (d) $8 \times 10^{17} \mathrm{~cm}^{-3}$, (e) $9 \times 10^{17} \mathrm{~cm}^{-3}$, (f) $1.5 \times 10^{18} \mathrm{~cm}^{-3}$, (g) $1 \times 10^{18} \mathrm{~cm}^{-3}$ and $(\mathrm{h}) 7 \times 10^{17} \mathrm{~cm}^{-3}$.The inset shows the electron concentrations due to $(\mathrm{g}) 1 \times 10^{18} \mathrm{~cm}^{-3}$ and $(\mathrm{h}) 7 \times$ $10^{17} \mathrm{~cm}^{-3}$, respectively. The growth parameters are: Substrate temperature $=700^{\circ} \mathrm{C}, \quad[\mathrm{TMGa}]=1.78 \times$ $10^{-4}$ and $\left[\mathrm{AsH}_{3}\right]=1.57 \times 10^{-2}$ and $\mathrm{SiH}_{4}$ partial pressure ranging from $1.24 \times 10^{-7}$ to $9 \times 10^{-5}$ Torr.

leads one to believe that possibly this PL band involves more than one emission. In these PL spectra, one can find that, as $\mathrm{Si}$ partial pressure increases the lower energy emissions are more favoured. These deep photoluminescence feature about $1.05-1.28 \mathrm{eV}$ has been attributed to a $\mathrm{Si}_{\mathrm{Ga}}-\mathrm{Si}_{\mathrm{As}}$ pair defects [8, 9]. The $1.20 \mathrm{eV}$ PL emission in GaAs has been extensively studied and is attributed to the complex $\left(\mathrm{Si}_{\mathrm{Ga}}-\mathrm{V}_{\mathrm{Ga}}\right)$ [18]. A peak at around $1.4894 \mathrm{eV}$ was observed at higher doping level, most clearly seen at the $\mathrm{SiH}_{4}$ partial pressure greater than $2.9 \times 10^{-5}$ Torr of inset Fig. 2 . The peak is probably associated with the shallow acceptor, $\mathrm{Si}_{\mathrm{As}}$ [18]. The broad, lower energy emission with a peak energy of $\approx 1.05 \mathrm{eV}$ (inset Fig. 2) is accompanied with the $\mathrm{Si}_{\mathrm{Ga}}-\mathrm{V}_{\mathrm{Ga}}$ complex for the highest $\mathrm{SiH}_{4}$ partial pressure. During the process of identifying of this characteristics emission it should be kept in mind that the $\mathrm{Si}$ concentration is high and that even $\mathrm{Si}$ precipitates have been formed [19]. Therefore, $\mathrm{Si}_{\mathrm{Ga}}$ atoms remain present in the solid and their concentration may even have increased at this higher $\mathrm{SiH}_{4}$ concentrations. Gallium vacancies, however, could have been occupied by additional $\mathrm{Si}$ atoms. Hence, the simplest mode of understanding is to replace the gallium vacancy in the $\mathrm{Si}_{\mathrm{Ga}}-\mathrm{V}_{\mathrm{Ga}}$ complex by a species which is likely to be enhanced at high $\mathrm{SiH}_{4}$ concentrations. The most likely candidate is $\mathrm{Si}_{\mathrm{As}}$, since the compensated character of the samples implies that also the $\mathrm{Si}_{\mathrm{As}}$ concentration increases as a function of $\mathrm{SiH}_{4}$ partial pressure. The characteristics emission at $1.05 \mathrm{eV}$ therefore may tentatively be attributed to the $\mathrm{Si}_{\mathrm{Ga}}-\mathrm{Si}_{\mathrm{As}}$ [9] complex. One can propose that $\mathrm{Si}$ atoms may be incorporated on both $\mathrm{Ga}\left(\mathrm{Si}_{\mathrm{Ga}}\right)$ and $\mathrm{As}$ $\left(\mathrm{Si}_{\mathrm{As}}\right)$ lattice sites and that, the proportional $\mathrm{Si}$ atoms occupying the latter sites increases at higher total $\mathrm{Si}$ concentration. $\mathrm{Si}_{\mathrm{As}}$ centers are acceptors and so the expected free carrier concentration would be given by $n=\left[\mathrm{Si}_{\mathrm{Ga}}\right]-\left[\mathrm{Si}_{\mathrm{As}}\right]$. From this figure, it can also be seen that there is no peak around $1.05-1.28 \mathrm{eV}$ on those samples grown below $\mathrm{SiH}_{4}$ partial pressure of $2.9 \times 10^{-5}$ Torr. Therefore, the peaks around $1.05-1.28 \mathrm{eV}$ were present in those samples grown only at the $\mathrm{SiH}_{4}$ partial pressures greater than $2.9 \times 10^{-5}$ Torr and indicates that the film is compensated. It is a direct observation of autocompensation, by photoluminescence spectroscopy and confirmed by electrical methods and vice versa.

Figure 3 shows the electron concentration and Hall mobility as a function of growth temperatures for a given

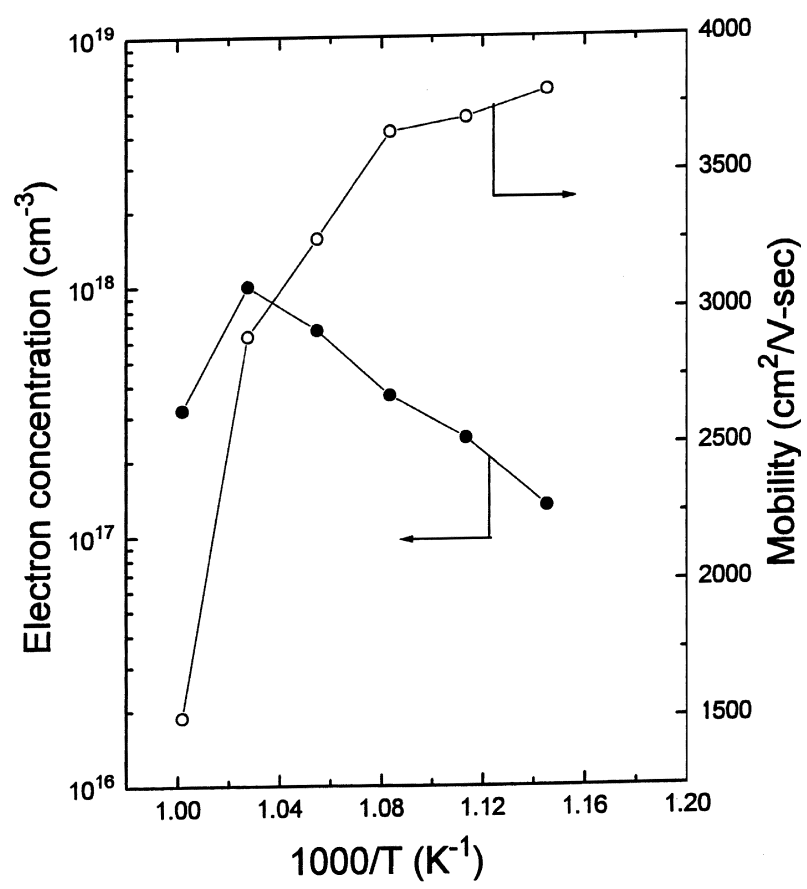

Fig. 3. $300 \mathrm{~K}$ electron concentrations and electron mobilities for Si-doped GaAs epilayers grown under various growth temperatures. The growth parameters are: $\left[\mathrm{SiH}_{4}\right]=5.18 \times 10^{-7}, \quad[\mathrm{TMGa}]=1.78 \times 10^{-4}$ and $\left[\mathrm{AsH}_{3}\right]=1.57 \times 10^{-2}$. 
TMGa, $\mathrm{SiH}_{4}$ and $\mathrm{AsH}_{3}$ mole fractions. The electron concentration is observed to increase as the growth temperature increases for a fixed $\mathrm{SiH}_{4}$ mole fraction and is believe to be a result of increasing decomposition rate of $\mathrm{SiH}_{4}$ with increasing temperature. The electron concentration is equivalent to the $\mathrm{Si}$ concentration in most cases $\left(n \approx[\mathrm{Si}]_{\mathrm{GaAs}}\right)$. The electron mobility exhibited a decrease with increasing growth temperature. From this figure, it is also seen that the electron concentration decreases with increasing growth temperature above $700^{\circ} \mathrm{C}$, due to autocompensation and is further confirmed by Hall mobility data. This autocompensation, can further be confirmed by LTPL spectroscopy of the effect of growth temperature on the photoluminescence spectra.

Figure 4 shows the photoluminescence spectra at $4.2 \mathrm{~K}$ for all the samples studied in Fig. 3. The excitonic PL main peak energy shifted to higher energy as the electron concentration increased, which is primarily due to Burstein-Moss effect. From the Fig. 3 it is seen that the sample is autocompensated when the growth temperature is greater than $700^{\circ} \mathrm{C}$ in our present growth conditions. The PL spectrum corresponding to the growth temperature $725^{\circ} \mathrm{C}$ is plotted inset in Fig. 4. The PL spectra shows a strong dependence on growth

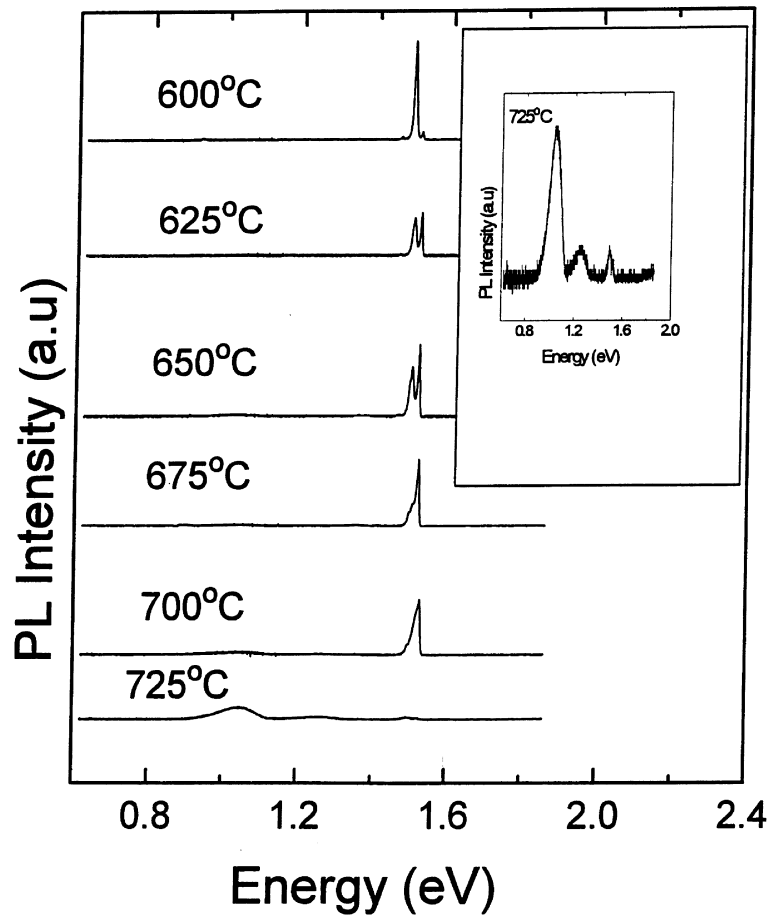

Fig. 4. 4.2 K PL spectra of Si-doped GaAs epilayers for various growth temperatures. The growth parameters are: $\left[\mathrm{SiH}_{4}\right]=5.18 \times 10^{-7}, \quad[\mathrm{TMGa}]=1.78 \times 10^{-4}$ and $\left[\mathrm{AsH}_{3}\right]=1.57 \times 10^{-2}$. The inset shows the PL spectrum corresponds to the growth temperature at $725^{\circ} \mathrm{C}$. temperature. From this figure, it can also be seen that there is no peak around $1.05-1.28 \mathrm{eV}$ on those samples grown below $700^{\circ} \mathrm{C}$, whereas the peak around $1.05-$ $1.28 \mathrm{eV}$ was present in the sample grown at $725^{\circ} \mathrm{C}$ (inset in Fig. 4). This observation confirms that the film is autocompensated grown above $700^{\circ} \mathrm{C}$ and exhibits consistently between the photoluminescence and electrical methods as well.

\section{CONCLUSIONS}

In conclusion, we have studied the Si doping in GaAs layers grown by MOVPE. Our results indicate the presence of $\mathrm{Si}$ complex defects, which are tentatively attributed to $\mathrm{Si}_{\mathrm{Ga}}-\mathrm{Si}_{\mathrm{As}}$. The $\mathrm{Si}_{\mathrm{Ga}}-\mathrm{Si}_{\mathrm{As}}$ pair defect is also present in heavily doped samples and also in the samples grown at higher growth temperatures. The photoluminescence spectra shows a strong dependence on electron concentration and growth temperatures. We have demonstrated the direct correlation of compensation in both electrical and optical methods.

\section{REFERENCES}

1. Van Zeghbroeck, B.J., Patrick, W., Meier, H. and Vettiger, P., IEEE Electron Devices Lett., EDL-8, $1987,118$.

2. Swaminathan, V., Sturge, M.D. and Zilko, J.L., J. Appl. Phys., 52, 1981, 6306.

3. Schubert, E.F., Göbel, E.O., Horikoshi, Y., Ploog, K. and Queisser, H.J., Phys. Rev., B30, 1984, 813.

4. Oh-hory, T., Itoh, H., Tanaka, H., Kasi, K., Takikawa, M. and Komeno, J., J. Appl. Phys., 61, 1987, 4603.

5. Adachi, S., J. Appl. Phys., 63, 1988, 64.

6. De Paula, Ana M., Medeiros-Ribeiro, G. and De Oliveira, A.G., J. Appl. Phys., 76, 1994, 8051.

7. Venkatasubramanian, R., Patel, K. and Ghandhi, S.K., J. Crystal Growth, 94, 1989, 34.

8. Souza, P.L. and Rao, E.V.K., J. Appl. Phys., 67, 1990, 7013.

9. Visser, E.P., Tang, X., Wieleman, R.W. and Giling, L.J., J. Appl. Phys., 69, 1991, 3266.

10. Maguire, J., Murray, R., Newman, R.C., Beall, R.B. and Harris, J.J., Appl. Phys. Lett., 50, 1987, 516.

11. Bass, S.J., J. Crystal Growth, 47, 1979, 613.

12. Schubert, E.F., Doping in III-V Semiconductors. Cambridge University Press, Cambridge, 1993.

13. Walukiewicz, W., Appl. Phys. Lett., 54, 1989, 2094.

14. Walukiewicz, W., Phys. Rev., B41, 1990, 10218.

15. Theis, T.N., Mooney, P.M. and Wright, S.L., Phys. Rev. Lett., 60, 1988, 361.

16. Fushimi, H., Shinohara, M. and Wada, K., J. Appl. Phys., 81, 1997, 1745. 
17. Burstein, E., Phys. Rev., 93, 1954, 632; Moss, T.S., Proc. Phys. Soc. London, B67, 1954, 775.

18. Williams, E.W. and Barry Bebb, H., in Semiconductors and Semimetals (Edited by R.K.
Willardson and A.C. Beer), Vol. 8, Chap. 5. Academic, New York, 1972.

19. Tang, X., Lochs, H.G.M., Hageman, P.R., de Croon, M.H.J.M., Giling, L.J. and Bons, A.J., J. Crystal Growth, 98, 1989, 827. 